\title{
Çeşitli gübre karışımı uygulamaları ve hasat zamanının kekik (Thymus sipyleus BOISS. subsp. sipyleus BOISS. var. sipyleus L.) bitkisinin ana uçucu bileşenleri üzerine etkileri
}

\author{
Samim Yaşar a,* (D), Nevriye Sicima (iD
}

\begin{abstract}
Özet: Kekik (Thymus sipyleus BOISS. subsp. sipyleus BOISS. var. sipyleus L.) bitkisi Beyşehir Muslu Yayla mevkiinden $1750 \mathrm{~m}$ yükseltiden doğal ortamından köklenerek, Beyşehir İslibucak mevkiinde 1345 m yükseltide kültüre alınmıştır. Kekik üretimi, Azot + Fosfor + Potasyum (K1), Mikro Elementler (Bor + Bakır + Demir + Mangan + Molibden + Cinko) (K3) ve Azot + Fosfor + Potasyum + Mikro Elementlerden (Bor + Bakır + Demir + Mangan + Molibden + Çinko) (K2 ve K4) oluşan gübre karışımlarının uygulanması ile gerçekleştirilmiștir. Kekik bitkisi örnekleri ağustos, eylül ve ekim 2019 aylarında üç ayrı dönemde hasat edilmiş ve uçucu bileşenlerinin analizinde SPME-GC-MS kullanılmıştır. Elde edilen sonuçlar, uygulanan gübre karışımlarının ve hasat döneminin kekik bitkisi ana uçucu bileşenlerinin miktarlarında çeșitlilik sağladığını göstermiștir. p-simenin (\%43.76) K4 gübre karışımı uygulamasının ekim hasadında, $\gamma$-terpinenin (\%24.79) K4 gübre karışımı uygulamasının ağustos hasadında, timolün (\%20.26) K3 gübre karışımı uygulamasının ağustos hasadında ve karvakrolün (\%67.01) K1 gübre karışımı uygulamasının eylül hasadında en yüksek değerlerde olduğu görülmüştür.

Anahtar kelimeler: Kekik, Gübre karışımı uygulamaları, Hasat zamanı, Uçucu bileşenler, SPME, GC-MS
\end{abstract}

\section{Effects of various fertilizer mixture applications and harvesting time on main volatile compounds of thyme (Thymus sipyleus BOISS. subsp. sipyleus BOISS. var. sipyleus L.)}

\begin{abstract}
The thyme (Thymus sipyleus BOISS. subsp. sipyleus BOISS. var. sipyleus L.) plant was rooted from its natural environment at an altitude of $1750 \mathrm{~m}$ from Beysehir Muslu Yayla location and was cultured at $1345 \mathrm{~m}$ altitude in Beysehir İslibucak. Nitrogen + Phosphorus + Potassium (K1), Micro Elements (Boron + Copper + Iron + Manganese + Molybdenum + Zinc) $($ K3) and Nitrogen + Phosphorus + Potassium + Micro Elements (Boron + Copper + Iron + Manganese + Molybdenum + Zinc) (K2 and K4) was used as fertilizer mixtures for thyme production. Plant samples were harvested in three separate periods in August, September and October 2019 and SPME-GC-MS was used for the analysis of its volatile components. The results showed that the applied fertilizer mixtures and the harvest period provided a variety in the amounts of the thyme plant main volatile components. The highest value of $p$-cymene $(43.76 \%)$ in the October harvest of thyme produced using K4 fertilizer mixture application, the highest value of $\gamma$-terpinene (24.79\%) in the August harvest of thyme produced using K4 fertilizer mixture application, the highest value of thymol (20.26\%) in the August harvest of thyme produced using K3 fertilizer mixture application and the highest value of carvacrol (67.01\%) in the September harvest of thyme produced using K1 fertilizer mixture application were observed.
\end{abstract}

Keywords: Thyme, Fertilizer mixture applications, Harvesting time, Volatile compounds, SPME, GC-MS

\section{Giriş}

Thymus L., Türkiye'de 39 tür ve 60 takson ile Lamiaceae (Labiatae) familyasının en geniş polimorfik cinslerinden birisi olup, endemiklik oran $\% 45$ olarak belirtilmiştir (Başer, 2002). Türkiye'de Thymus türleri "Kekik" olarak adlandırılmaktadır. Kurutulan bitki kısımları çay ve aroma maddesi olarak tüketilmektedir. Geleneksel yöntemle elde edilen Thymus uçucu yağı, değerli bileşenleri nedeniyle yerel halk tarafından sıklıkla tıbbi amaçlara yönelik kullanılmaktadır (Başer, 2001). Thymus sipyleus BOISS. subsp. sipyleus BOISS. var. sipyleus L., 400-2700 m yükseltilerde dağ bozkırları ve kayalık yamaçlarda yetişen çok yıllık, yarıçalı formunda ve 5-8 adet çiçeklenmeye sahip bir bitki olup, Türkiye'de ve Ege adalarında oldukça geniş yayılış göstermektedir (Tübives, 2021).

Katı faz mikro ekstraksiyonu (SPME), uçucu bileşenlerin kaplanmış bir silika lifin yüzeyine tutulduğu analitik bir teknik olarak bilinmektedir. SPME aparatı modifiye edilmiş bir şırıngaya benzemektedir. İç kısmında uçucu bileşenleri tutmaya yarayan bir life sahip olan SPME iğnesi, kapalı durumda 1 sitılmış numunenin serbest bıraktı̆̆ bileşenlerin bulunduğu atmosfere sokulmakta ve lifi koruyan metal iğne geri çekilerek lifin atmosferle teması sağlanmaktadır. Lif üzerindeki polimer kaplamanın (Carbokzen/Polidimetilsilokzan) absorpsiyon/adsorpsiyon

$\begin{array}{lll}\bigotimes & \text { a } & \text { Isparta Uygulamalı Bilimler Üniversitesi, Orman Fakültesi, Isparta } \\ @ & * & \text { Corresponding author (İletişim yazarı): samimyasar@isparta.edu.tr } \\ \checkmark & \text { Received (Geliş tarihi): 09.03.2021, Accepted (Kabul tarihi): 20.04.2021 }\end{array}$ 
yöntemiyle uçucu bileşenleri almasından sonra koruma amaçlı olarak lif tekrar metal iğnenin içerisine çekilmektedir. Bunu, bileşenlerin ayırılması için uygun bir kromatografi cihazına desorpsiyonu takip etmektedir. SPME uygulamaları, genellikle GC (Gaz Kromatografisi) veya GC-MS (Gaz Kromatografisi-Kütle spektroskopisi) ile yapılmaktadır. SPME-GC veya SPME-GC-MS analizinde, lif cihazın enjektör portuna yerleştirilmekte ve uçucu bileşenlerin kromatografik tayini için termal desorpsiyon gerçekleştirilmektedir (Galipo vd., 1999; Malik vd., 2006).

Çözücüye ihtiyaç duymayan bir izolasyon tekniği olan SPME, 1989'daki icadından itibaren uçucu ve yarı uçucu organik bileşiklerin ekstraksiyonunda sıklıkla kullanılmıştır (Belardi ve Pawliszyn, 1989; James ve Stack, 1996; Malik vd., 2006; Yaşar vd., 2016). Erken gelişim döneminde, SPME büyük ölçüde çevre kimyasında uygulanmıştır (Fattore vd., 1996; Abalos vd., 2002; Mousavi vd., 2007). Son yıllarda, GC veya GC-MS ile birlikte bitkisel kökenli örneklerdeki uçucu ve yarı uçucu organik bileşiklerin ekstraksiyonunda bu teknikten siklıkla faydalanılmaktadır (Vas ve Vekey, 2004; Yaşar vd., 2016).

Aromatik bitkilerde bitki verimi, drog verimi, uçucu yağ içeriği ve bileşimi üzerinde yetiştirme koşulları, iklim koşulları, bitkilerin büyüme periyodu, genetik modifikasyonlar ve tarımsal uygulamalar gibi faktörler etkili olmaktadır (Lawrence, 1993; Perry vd., 1999; GrausgruberGröger vd., 2012). Tarımsal uygulamalardan özellikle fosfor aromatik bitkilerde uçucu yağ sentezi ve asimilasyonunda önemli rolü olan bitki besin elementlerinden bir tanesidir. Farnesil difosfat, geranil difosfat ile linalol difosfata indirgenmekte ve bu bileşenler uçucu yağ üretiminin ön sentezleyici bileşenleri olarak karşımıza çıkmaktadır (Ramezani vd., 2009). Kimyon, rezene, adaçayı, kekik, fesleğen ve kişniş gibi aromatik bitkilerde gübre uygulamalarının uçucu yağ içeriği ve verimini artırdığı belirtilmiştir (Tunçturk ve Tunçturk 2006; Moslemi vd., 2012; Nell vd., 2009; Meena vd., 2015).

Çalışmamızda, doğal ortamından köklenen kekik (Thymus sipyleus BOISS. subsp. sipyleus BOISS. var. sipyleus L.) bitkisi, kültüre alındıktan sonra çeşitli gübre karışımı uygulamalarına tabi tutulmuş ve farklı zamanlarda ürün hasadı gerçekleştirilmiştir. Bitki örneklerinin uçucu bileşenleri SPME ile izole edilmiş ve GC-MS ile analizleri gerçekleştirilmiştir. Söz konusu gübreleme uygulamaları ve hasat zamanlarının kekik bitkisi ana uçucu bileşenlerinin miktarlarına etkileri incelenmiştir.

\section{Materyal ve yöntem}

\subsection{Bitki yetiştirme ve materyal toplama}

Kekik bitkisi, Beyşehir Muslu Yayla mevkiinden 1750 m yükseltiden 23.05.2019 tarihinde doğal ortamından köklenerek, kültüre alınacağı Beyşehir İslibucak mevkiine (1345 m yükselti) getirilmiştir. Deneme alanı açık arazide kurulmuştur. 24.06.2019 tarihine kadarki köklendirme sürecinde herhangi bir müdahale gerçekleştirilmemiş, sadece sulama işlemi yapılmıştır. Sonrasında, gübreleme uygulamalarına başlanmıştır. Kekik üretiminde kullanılan gübre karışım ve miktarları Çizelge 1 ve uygulanan gübreleme parametreleri Çizelge 2'de verilmiştir. Örnekler birer ay arayla üç dönem halinde 02.08.2019, 02.09.2019 ve 02.10.2019 tarihlerinde hasat edilmiştir. Bitkilerin toplanan toprak üstü kısımları oda sıcaklığında ve karanlık ortamda sabit ağırlığa kurutulmuştur.

\subsection{Yöntem}

\subsubsection{SPME}

Kullanılan katı faz mikro ekstraksiyon (SPME) aparatı, $75 \mu \mathrm{m}$ kalınlığında Carbokzen/Polidimetilsilokzan (CAR/PDMS) ile kaplanmış kısımdan oluşmaktadır. Kurutulan kekik örneklerinin her birinin 2.5 g'1 uçucu bileşen analizleri için $10 \mathrm{~mL}$ 'lik bir vial içine aktarılmış ve vialin ağzı silikon bir kapakla kapatılmış, sonrasında 30 dakika süreyle $60{ }^{\circ} \mathrm{C}^{\prime} \mathrm{de}$ bekletilmiştir.

\subsection{2. $G C-M S$}

SPME aparatı, uçucu bileşenlerin adsorbsiyonu için vialin üst tarafında kalan atmosfere geçirilmiş ve daha sonra Restek Rx-5Sil MS kapiler kolon (30 m x 0.25 mm i.d., 0.25 $\mu \mathrm{m}$ film kalınlığı) kullanılan, Shimadzu 2010 Plus GC-MS cihazına uçucu bileşenlerin desorpsiyonu için doğrudan bağlanmıştır. Cihaz, EI modunda $(70 \mathrm{eV})$ çalıştırılan aynı marka kütle seçici dedektörle irtibatlandırılmıştır. Taşıyıcı gaz olarak helyum dakikada $1.61 \mathrm{~mL}$ akış hızında uygulanmıştır. Enjeksiyon ve dedeksiyon sıcaklıkları $250{ }^{\circ} \mathrm{C}$ olarak programlanmıştır. Kolon sıcaklığı, 2 dakika boyunca $40{ }^{\circ} \mathrm{C}$ 'de sabitlenmiş, devamında dakikada $4{ }^{\circ} \mathrm{C}$ artışla 250 ${ }^{\circ} \mathrm{C}$ ye ulaştırılmış, sonrasında $230{ }^{\circ} \mathrm{C}^{\prime}$ de 5 dakika boyunca bekletilmiştir.

Çizelge 1. Kekik üretiminde kullanılan gübre karışım ve miktarları

\begin{tabular}{|c|c|c|c|}
\hline \multirow{2}{*}{ Örnek } & \multicolumn{3}{|c|}{ Gübreleme uygulamaları } \\
\hline & Bitki adedi & Gübre çeşidi & Gübre miktarı (g/bitki) \\
\hline K1 & 5 & Azot+Fosfor+Potasyum & $2+2+2=6$ \\
\hline $\mathrm{K} 2$ & 5 & Azot+Fosfor+Potasyum+Mikro Elementler (Bor+Bakır+Demir+Mangan+Molibden+Çinko) & $2+2+2+0.25=6.25$ \\
\hline $\mathrm{K} 3$ & 5 & Mikro Elementler (Bor+Bakır+Demir+Mangan+Molibden+Çinko) & 0.25 \\
\hline K4 & 5 & Azot+Fosfor+Potasyum+Mikro Elementler (Bor+Bakır+Demir+Mangan+Molibden+Çinko) & $2+2+2+0.25=6.25$ \\
\hline K0 & Doğal ortam & Inda takibi yapılıp, toplanan örnek (Kontrol) & \\
\hline
\end{tabular}

Çizelge 2. Kekik üretiminde uygulanan gübreleme parametreleri

\begin{tabular}{clcc}
\hline \multirow{2}{*}{ Örnek } & \multicolumn{3}{c}{ Gübreleme parametreleri } \\
\cline { 2 - 4 } & Şekli & Periyod & Verilen sıv1 miktarı (L/bitki) \\
\hline K1 & Topraktan Gübreli Su & 5 gün & 2 \\
K2 & Topraktan Gübreli Su & 5 gün & 2 \\
K3 & Topraktan Gübreli Su & 5 gün & $17: 00-20: 00$ aras1 \\
K4 & Topraktan Bir Sulamada Gübreli Su, Bir Sulamada Tatlı Su & 5 gün & 2 \\
\hline
\end{tabular}




\subsubsection{Uçucu bileşenlerin tanımlanması}

Uçucu bileşenlerin Alıkonma İndisleri (RI), örneklerin analizinde uygulanan kromatografik koşullarda enjeksiyonu gerçekleştirilen $\mathrm{C}_{7}-\mathrm{C}_{30}$ alkan karışımı standardına göre belirlenmiştir. Uçucu bileşenlerin saptanmasında Wiley, NIST Tutor ve FFNSC kütüphanelerinden faydalanılmıştır.

\subsection{Istatistiksel analiz}

Çalışma verilerine istatistiksel analiz MiniTab 16 programı yardımıyla uygulanmıştır. Basit varyans analizi (Anova Testi) yapılmış ve istatiksel açıdan farklılaşmanın gerçekleşmesi durumunda, veriler arasındaki farklılıklar Duncan Çoklu Karşılaştırma Testi ile belirlenmiştir.

\section{Bulgular ve tartışma}

Farklı gübre karışımı uygulamalarının kekik bitkisi örneklerindeki $p$-simen, $\gamma$-terpinen, timol ve karvakrol miktarları üzerine etkileri Çizelge 3'te verilmiştir. Miktarların aritmetik ortalamalarının kontrolü basit varyans analizi (Anova testi) ile yapılmış ve $\mathrm{p}<0.001$ düzeyinde Duncan testine göre elde edilen homojen gruplar gösterilmiştir.

$p$-simen miktarında, ağustos ve eylül hasatlarında $\mathrm{K} 0$ örneğine göre gübreleme uygulamalarına ait örneklerde belirgin bir şekilde düşüş görülmüş, ekim hasadında ise K4 örneğinde artış, diğer gübreleme uygulamaları örneklerinde düşüş belirlenmiştir. $\gamma$-terpinen miktarı eylül ve ekim hasatlarında K0 örneğine göre gübreleme uygulamalarına ait örneklerde artış göstermiştir. Timol miktarı K3 gübreleme örneğinde, diğer örneklere kıyasla her üç hasat döneminde de net bir şekilde üstünlük sergilemiştir. Karvakrol miktarı ağustos ve eylül hasatlarında $\mathrm{K} 1, \mathrm{~K} 2$ ve $\mathrm{K} 4$ gübreleme uygulamaları örneklerinde, ekim hasadında K1 ve K2 gübreleme uygulamaları örneklerinde yüksek düzeylerde yer almıştır (Çizelge 3).

Farklı hasat zamanlarının kekik bitkisi örneklerindeki $p$ simen, $\gamma$-terpinen, timol ve karvakrol miktarları üzerine etkileri Çizelge 4'de verilmiştir. Miktarların aritmetik ortalamalarının kontrolü basit varyans analizi (Anova testi) ile yapılmış ve $\mathrm{p}<0.001$ düzeyinde Duncan testine göre elde edilen homojen gruplar sunulmuştur.

$p$-simen miktarı K2 gübreleme uygulamasında eylül hasadı örneğinde, ağustos hasadı örneğine göre düşüş gösterirken, ekim hasadı örneğinde artış sergilemiştir. K0 ve diğer gübreleme uygulamalarında, $p$-simen miktarı ağustos hasadı örneğine kıyasla eylül ve ekim hasadı örneklerinde belirgin bir şekilde artış ortaya koymuştur. $\gamma$-terpinen miktarı K0 ve tüm gübreleme uygulamalarında ağustos hasadı örneğine göre, eylül ve ekim hasadı örneklerinde düşüş göstermiştir. Timol miktarı K2 gübreleme uygulamasında ağustos hasadı örneğine göre, eylül hasadı örneğinde yükseliş, ekim hasadı örneğinde azalış, K3 gübreleme uygulamasında ağustos hasadı örneğine göre, eylül ve ekim hasadı örneklerinde düşüş, K0 ve diğer uygulamalarda ağustos hasadı örneğine göre, eylül ve ekim hasadı örneklerinde artış sergilemiştir. Karvakrol miktarı K0 ve gübreleme uygulamalarında ağustos ve eylül hasadı örneklerinde, ekim hasadı örneklerine kıyasla yüksek seviyelerde elde edilmiştir (Çizelge 4).

$p$-simen \% 43.76 ile $\mathrm{K} 4$ gübreleme uygulamasının ekim hasadı, $\gamma$-terpinen \%24.79 ile K4 gübreleme uygulamasının ağustos hasad1, timol $\% 20.26$ ile K3 gübreleme uygulamasının ağustos hasadı ve karvakrol \%67.01 ile K1 gübreleme uygulamasının eylül hasadı örneğinde en yüksek değerde elde edilmiştir (Şekil 1).

Çizelge 3. Gübrelemenin kekik bitkisi örneklerinin ana bileşenlerine etkileri

\begin{tabular}{|c|c|c|c|c|c|}
\hline Bileșen (RI) & $\mathrm{KO}(\%)$ & $\mathrm{K} 1(\%)$ & $\mathrm{K} 2(\%)$ & K3 (\%) & $\mathrm{K} 4(\%)$ \\
\hline \multicolumn{6}{|l|}{ Ağustos hasadı } \\
\hline$p$-simen (1025) & $16.16 \mathrm{a}$ & $5.21 \mathrm{~b}$ & $10.88 \mathrm{c}$ & $6.26 \mathrm{~d}$ & $6.55 \mathrm{e}$ \\
\hline$\gamma$-terpinen $(1058)$ & $20.78 \mathrm{a}$ & $23.80 \mathrm{~b}$ & $21.61 \mathrm{c}$ & $17.99 \mathrm{~d}$ & $24.79 \mathrm{e}$ \\
\hline Timol (1300) & $0.17 \mathrm{a}$ & $0.25 \mathrm{~b}$ & $0.17 \mathrm{a}$ & $20.26 \mathrm{c}$ & $1.71 \mathrm{~d}$ \\
\hline Karvakrol (1317) & $36.57 \mathrm{a}$ & $50.09 \mathrm{~b}$ & $43.63 \mathrm{c}$ & $30.21 \mathrm{~d}$ & $43.10 \mathrm{e}$ \\
\hline \multicolumn{6}{|l|}{ Eylül hasadı } \\
\hline$p$-simen & $34.28 \mathrm{a}$ & $7.84 \mathrm{~b}$ & $7.67 \mathrm{c}$ & $7.49 \mathrm{~d}$ & $8.91 \mathrm{e}$ \\
\hline$\gamma$-terpinen & $1.84 \mathrm{a}$ & $7.87 \mathrm{~b}$ & $10.81 \mathrm{c}$ & $12.73 \mathrm{~d}$ & $20.32 \mathrm{e}$ \\
\hline Timol & $0.91 \mathrm{a}$ & $0.66 \mathrm{~b}$ & $0.36 \mathrm{c}$ & $18.60 \mathrm{~d}$ & $4.36 \mathrm{e}$ \\
\hline Karvakrol & $34.12 \mathrm{a}$ & $67.01 \mathrm{~b}$ & $52.81 \mathrm{c}$ & $40.33 \mathrm{~d}$ & $45.78 \mathrm{e}$ \\
\hline \multicolumn{6}{|l|}{ Ekim hasadı } \\
\hline$p$-simen & $38.36 \mathrm{a}$ & $23.45 \mathrm{~b}$ & $24.16 \mathrm{c}$ & $27.56 \mathrm{~d}$ & $43.76 \mathrm{e}$ \\
\hline$\gamma$-terpinen & $3.72 \mathrm{a}$ & $7.76 \mathrm{~b}$ & $10.11 \mathrm{c}$ & $8.65 \mathrm{~d}$ & $8.85 \mathrm{e}$ \\
\hline Timol & $4.38 \mathrm{a}$ & $6.55 \mathrm{~b}$ & $0.14 \mathrm{c}$ & $13.06 \mathrm{~d}$ & $5.34 \mathrm{e}$ \\
\hline Karvakrol & $27.15 \mathrm{a}$ & $41.18 \mathrm{~b}$ & $40.86 \mathrm{c}$ & $26.66 \mathrm{~d}$ & $23.29 \mathrm{e}$ \\
\hline
\end{tabular}

RI: Alıkonma indisi, a-e: Duncan testi homojen grupları, $\mathrm{p}<0.001$ 
Çizelge 4. Hasat zamanının kekik bitkisi örneklerinin ana bileşenlerine etkileri

\begin{tabular}{|c|c|c|c|}
\hline Bileşen (RI) & Ağustos hasadı (\%) & Eylül hasadı (\%) & Ekim hasadı (\%) \\
\hline \multicolumn{4}{|l|}{$\mathrm{KO}$} \\
\hline$p$-simen (1025) & $16.16 \mathrm{a}$ & $34.28 \mathrm{~b}$ & $38.36 \mathrm{c}$ \\
\hline$\gamma$-terpinen $(1058)$ & $20.78 \mathrm{a}$ & $1.84 \mathrm{~b}$ & $3.72 \mathrm{c}$ \\
\hline Timol (1300) & $0.17 \mathrm{a}$ & $0.91 \mathrm{~b}$ & $4.38 \mathrm{c}$ \\
\hline Karvakrol (1317) & $36.57 \mathrm{a}$ & $34.12 \mathrm{~b}$ & $27.15 \mathrm{c}$ \\
\hline \multicolumn{4}{|l|}{ K1 } \\
\hline$p$-simen & $5.21 \mathrm{a}$ & $7.84 \mathrm{~b}$ & $23.45 \mathrm{c}$ \\
\hline$\gamma$-terpinen & $23.80 \mathrm{a}$ & $7.87 \mathrm{~b}$ & $7.76 \mathrm{c}$ \\
\hline Timol & $0.25 \mathrm{a}$ & $0.66 \mathrm{~b}$ & $6.55 \mathrm{c}$ \\
\hline Karvakrol & $50.09 \mathrm{a}$ & $67.01 \mathrm{~b}$ & $41.18 \mathrm{c}$ \\
\hline \multicolumn{4}{|l|}{$\mathrm{K} 2$} \\
\hline$p$-simen & $10.88 \mathrm{a}$ & $7.67 \mathrm{~b}$ & $24.16 \mathrm{c}$ \\
\hline$\gamma$-terpinen & $21.61 \mathrm{a}$ & $10.81 \mathrm{~b}$ & $10.11 \mathrm{c}$ \\
\hline Timol & $0.17 \mathrm{a}$ & $0.36 \mathrm{~b}$ & $0.14 \mathrm{c}$ \\
\hline Karvakrol & $43.63 \mathrm{a}$ & $52.81 \mathrm{~b}$ & $40.86 \mathrm{c}$ \\
\hline \multicolumn{4}{|l|}{ K3 } \\
\hline$p$-simen & $6.26 \mathrm{a}$ & $7.49 \mathrm{~b}$ & $27.56 \mathrm{c}$ \\
\hline$\gamma$-terpinen & $17.99 \mathrm{a}$ & $12.73 \mathrm{~b}$ & $8.65 \mathrm{c}$ \\
\hline Timol & $20.26 \mathrm{a}$ & $18.60 \mathrm{~b}$ & $13.06 \mathrm{c}$ \\
\hline Karvakrol & $30.21 \mathrm{a}$ & $40.33 \mathrm{~b}$ & $26.66 \mathrm{c}$ \\
\hline \multicolumn{4}{|l|}{ K4 } \\
\hline$p$-simen & $6.55 \mathrm{a}$ & $8.91 \mathrm{~b}$ & $43.76 \mathrm{c}$ \\
\hline$\gamma$-terpinen & $24.79 \mathrm{a}$ & $20.32 b$ & $8.85 \mathrm{c}$ \\
\hline Timol & $1.71 \mathrm{a}$ & $4.36 \mathrm{~b}$ & $5.34 \mathrm{c}$ \\
\hline Karvakrol & $43.10 \mathrm{a}$ & $45.78 \mathrm{~b}$ & $23.29 \mathrm{c}$ \\
\hline
\end{tabular}

RI: Alıkonma indisi, a-c: Duncan testi homojen grupları, $\mathrm{p}<0.001$
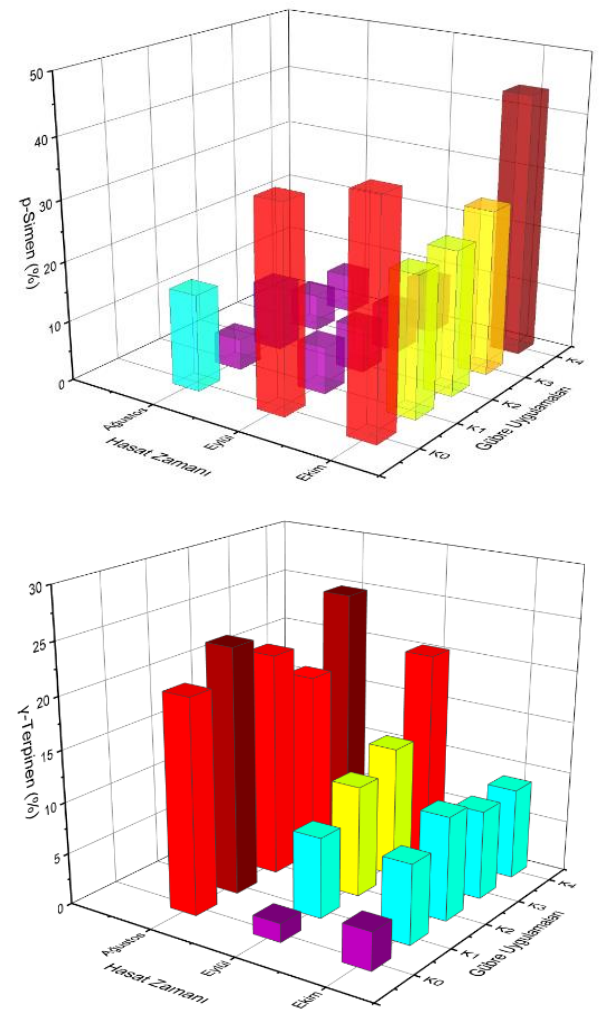

Şekil 1. Kekik bitkisi örneklerinin ana bileşenleri

p-simen, doğada bulunan, özellikle kekik türlerinde baskın olan bir monoterpen bileşiğidir (Philis, 2005). Bu bileşik, antioksidan, antinosiseptif, anti-enflamatuar, anksiyolitik, antikanser ve antimikrobiyal aktiviteleri içeren çeşitli biyolojik etkiler göstermektedir (De Oliveira vd., 2015). Ayrica, $p$-simenin antibakteriyel, antiviral ve
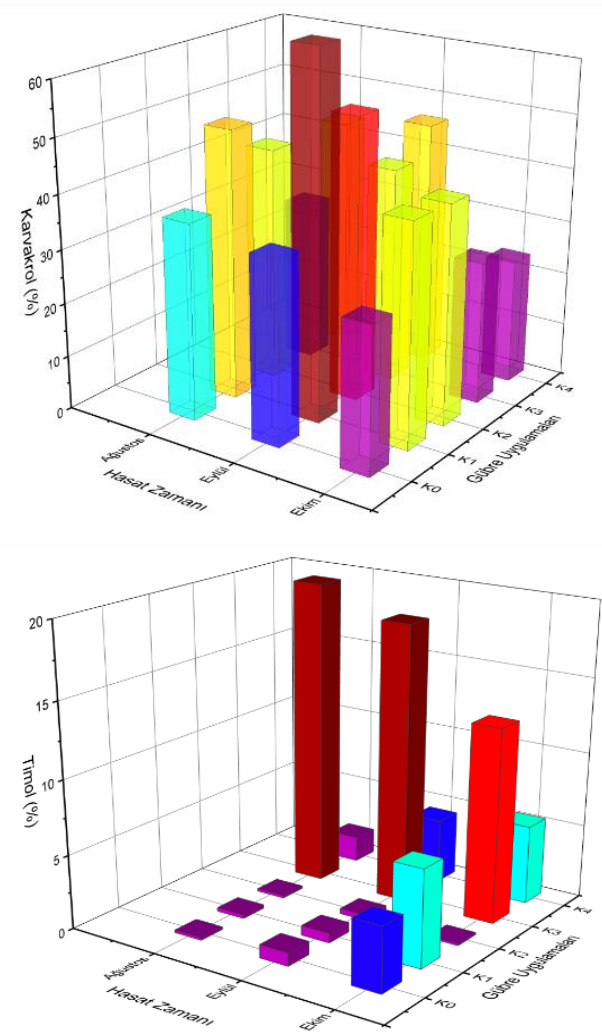

antifungal aktivitelere de sahip olduğu bilinmektedir (Marchese vd., 2017).

$\gamma$-terpinen bitkisel kökenli bir monoterpen hidrokarbon olup, çeşitli insan patojenlerine karşı antimikrobiyal özellikler göstermektedir (Pereira vd., 2014). Aynı zamanda $\gamma$-terpinenin antioksidan, anti-enflamatuar ve anti-proliferatif aktiviteleri ortaya konmuştur (Kavoosi vd., 2013). 
Timol, fenolik bir monoterpen alkol bileşiğidir. Timol'ün diğer fenollere göre 30 kat daha fazla antiseptik ve 4 kat daha az toksik etkisi olduğu belirlenmiştir (Lukic, 1989). Parfümeri ve kozmetik sanayinde timol problemli ciltlerin tedavisinde kullanılmaktadır. Ayrıca, timolün antimikrobiyel (Timbermont vd., 2010) ve antioksidan (Luna vd., 2010) aktivite gösterdiği tespit edilmiştir. Timol hızla bozunan, kalıcı olmayan bir pestisit olarak kullanım alanı bulmaktadır (Hu ve Coats, 2008; Nieto, 2017). Timolden tıbbi dezenfektan ve genel amaçlı dezenfektan olarak da faydalanılmaktadır (Novy vd., 2015).

Karvakrol, kekik ve kekik gibi Lamiaceae familyasına ait aromatik bitkilerin uçucu yağ fraksiyonundaki ana doğal bileşendir. $\gamma$-terpinenden, $p$-simen yoluyla biyosentezlenen fenolik bir monoterpen alkoldür (Kintzios, 2002). Gida, baharat ve ilaç endüstrilerinde kullanılan kekiğin biyolojik aktivitelerinin karvakrol içeriği ile paralel olduğu ileri sürülmüştür (Burt, 2004). Karvakrol içeren ilaçlar ve uçucu yağlar geleneksel tıpta yaygın olarak kullanılmaktadır (Edris, 2007). Karvakrolün fungisidal (Ahmad vd., 2011; Dambolena vd., 2011), insektisidal (Tang vd., 2011) ve antimikrobiyal aktiviteler (Nostro ve Papalia, 2012) sergilediği belirlenmiştir. Karvakrolün antikarsinojenik ve antitümör aktivitelerine (Koparal ve Zeytinoglu, 2003; Karkabounas vd., 2006), güçlü antimutajenik etkilerine ve antioksidan özelliklerine (Mezzoug vd., 2007; Sökmen vd., 2004) atfedilen çalışmalar rapor edilmiştir.

Çalışmada, kekik (Thymus sipyleus BOISS. subsp. sipyleus BOISS. var. sipyleus L.) üretiminde çeşitli gübre karışımlarının kullanılması ve bitkinin farklı zamanlarda hasat edilmesi ile ana uçucu bileşenlerinin miktarlarında çeşitlilik sağlanabileceği görülmüştür. Bu vesileyle, kullanım alanına yönelik ana bileşenlerin yüksek oranlarda elde edilebilmesinin, gübre karışımı uygulamaları ve hasat zamanının belirlenmesi ile mümkün olabileceği anlaşılmıştır.

\section{Sonuç ve öneriler}

Kekik (Thymus sipyleus BOISS. subsp. sipyleus BOISS. var. sipyleus L.) bitkisi doğal ortamından köklenerek, kültüre alınmış ve üretiminde Azot + Fosfor + Potasyum (K1), Mikro Elementler (Bor + Bakır + Demir + Mangan + Molibden + Çinko) (K3) ve Azot + Fosfor + Potasyum + Mikro Elementler (Bor + Bakır + Demir + Mangan + Molibden + Çinko) (K2 ve K4) gübre karışımları uygulanmıştır. Kekik bitkisinin ağustos, eylül ve ekim 2019 aylarında üç ayrı dönemde hasadı gerçekleştirilmiştir. Uygulanan gübre karışımlarının ve hasat döneminin kekik bitkisi ana uçucu bileşenlerinin miktarlarında çeşitlilik sağladığı anlaşılmıştır. $p$-simenin \% 43.76 ile $\mathrm{K} 4$ gübre karışımı uygulamasının ekim hasadı, $\gamma$-terpinenin $\% 24.79$ ile $\mathrm{K} 4$ gübre karışımı uygulamasının ağustos hasadı, timolün \%20.26 ile K3 gübre karışımı uygulamasının ağustos hasadı ve karvakrolün \%67.01 ile K1 gübre karışımı uygulamasının eylül hasadından en yüksek değerlerde elde edilebileceği görülmüştür.

\section{Açıklama}

$\mathrm{Bu}$ çalışma, Isparta Uygulamalı Bilimler Üniversitesi BAP Koordinasyon Birimi tarafindan 2019-YL1-0039 nolu proje ile desteklenmiştir. Bu destekten dolayı Isparta Uygulamalı Bilimler Üniversitesi BAP Koordinasyon Birimi’ne teşekkür ediyoruz.

\section{Kaynaklar}

Abalos, M., Prieto, X., Bayona, J.M., 2002. Determination of volatile alkyl sulfides in wastewater by headspace solid-phase microextraction followed by gas chromatography-mass spectrometry. Journal of Chromatography A, 963(1-2): 249-257.

Ahmad, A., Khan, A., Akhtar, F., Yousuf, S., Xess, I., Khan, L.A., Manzoor, N., 2011. Fungicidal activity of thymol and carvacrol by disrupting ergosterol biosynthesis and membrane integrity against Candida. European Journal of Clinical Microbiology \& Infectious Diseases, 30(1): 41-50.

Başer, K.H.C., 2001. Her derde deva bir bitki Kekik. Bilim ve Teknik, 2001: 74-77.

Başer, K.H.C., 2002. Aromatic biodiversity among the flowering plant taxa of Turkey. Pure and Applied Chemistry, 74(4): 527545.

Belardi, R.P., Pawliszyn, J.B., 1989. Application of chemically modified fused silica fibers in the extraction of organics from water matrix saples and their rapid transfer to capillary columns. Water Quality Research Journal, 24(1): 179-191.

Burt, S., 2004. Essential oils: Their antibacterial properties and potential applications in foods-a review. International Journal of Food Microbiology, 94(3): 223-253.

Dambolena, J.S., Zygadlo, J.A., Rubinstein, H.R., 2011. Antifumonisin activity of natural phenolic compounds. A structure-property-activity relationship study. International Journal of Food Microbiology, 145: 140-146.

De Oliveira, T.M., de Carvalho, R.B.F., da Costa, I.H.F., de Oliveira, G.A.L., de Souza, A.A., de Lima, S.G., de Freitas, R.M., 2015. Evaluation of p-cymene, a natural antioxidant. Pharmaceutical Biology, 53(3): 423-428.

Edris, A.E., 2007. Pharmaceutical and therapeutic potentials of essential oils and their individual volatile constituents: A review. Phytotherapy Research: An International Journal Devoted to Pharmacological and Toxicological Evaluation of Natural Product Derivatives, 21(4): 308-323.

Fattore, E., Benfenati, E., Fanelli, R., 1996. Analysis of chlorinated 1,3-butadienes by solid-phase microextraction and gas chromatography-mass spectrometry. Journal of Chromatography A, 737(1): 85-91.

Galipo, R.C., Canhoto, A.J., Walla, M.D., Morgan, S.L., 1999. Analysis of volatile fragrance and flavor compounds by headspace solid phase microextraction and GC-MS: An undergraduate instrumental analysis experiment. Journal of Chemical Education, 76(2): 245-248.

Grausgruber-Groger, S., Schmiderer, C., Steinborn, R., Novak, J., 2012. Seasonal influence on gene expression of monoterpene syntheses in Salvia officinalis (Lamiaceae). Journal of Plant Physiology, 169(4): 353-359.

Hu, D., Coats, J., 2008. Evaluation of the environmental fate of thymol and phenethyl propionate in the laboratory. Pest Management Science: formerly Pesticide Science, 64(7): 775779 .

James, K.J., Stack, M.A., 1996. The determination of volatile organic compounds in soils using solid phase microextraction with gas chromatography. Journal of High Resolution Chromatography, 19(9): 515-519.

Karkabounas, S., Kostoula, O.K., Daskalou, T., Veltsistas, P., Karamouzis, M., Zelovitis, I., Metsios, A., Lekkas, P., Evangelou, A.M., Kotsis, N., Skoufos, I., 2006. Anticarcinogenic and antiplatelet effects of carvacrol. Experimental Oncology, 28: 121-125.

Kavoosi, G., Tafsiry, A., Ebdam, A.A, Rowshan, V., 2013. Evaluation of antioxidant and antimicrobial activities of essential oils from carum copticum seed and Ferula assafoetida latex. Journal of Food Science, 78(2): T356-T361.

Kintzios, S.E., 2002. Oregano: The Genera Origanum and Lippia. Taylor and Francis, New York, NY, USA.

Koparal, A.T., Zeytinoglu, M., 2003. Effects of carvacrol on a human non-small cell lung cancer (nsclc) cell line, A549. Cytotechnology, 43: 149-154. 
Lawrence, B.M., 1993. Progress in essential oils, lavender oils. Perfumer and Flavorist, 18(1): 58-61.

Lukic, P., 1989. In: Farmacognazija, Farmaceutski facultet Univerziteta u Beogradu.

Luna, A., Labaque, M.C., Zygadlo, J.A., Marin, R.H., 2010. Effects of thymol and carvacrol feed supplementation on lipid oxidation in broiler meat. Poultry Science, 89: 366-370.

Malik, A.K., Kaur, V., Verma, N., 2006. A review on solid phase microextraction-high performance liquid chromatography as a novel tool for the analysis of toxic metal ions. Talanta, 68: 842849.

Marchese, A., Arciola, C.N., Barbieri, R., Silva, A.S., Nabavi, S.F., Sokeng, N.A.J.T., Izadi, M., Jafari, N.J., Suntar, I., Daglia, M., Nabavi, S.M., 2017. Update on monoterpenes as antimicrobial agents: A particular focus on p-cymene. Materials, 10(8): 947.

Meena, R.L., Meena, S.S., Mehta, R.S., Meena, R.D., Saini, Y., 2015. Response of varying nitrogen and phosphorus levels on growth and yield of anise (Pimpinella anisum L.). International Journal of Seed Spices, 5(1): 83-87.

Mezzoug, N., Elhadri, A., Dallouh, A., Amkiss, S., Skali, N.S., Abrini, J., Zhiri, A., Baudoux, D., Diallo, B., El Jaziri, M., Idaomar, M., 2007. Investigation of the mutagenic and antimutagenic effects of Origanum compactum essential oil and some of its constituents. Mutation Research/Genetic Toxicology and Environmental Mutagenesis, 629(2): 100-110.

Moslemi, M., Aboutalebi, A., Hamed, A., Farah, H., 2012. Evaluation the effects of different levels of phosphorous on yield and yield components of coriander (Coriandrum sativum L.). World Applied Sciences Journal, 19(11): 1621-1624.

Mousavi, M., Noroozian, E., Jalali-Heravi, M., Mollahosseini, A., 2007. Optimization of solid-phase microextraction of volatile phenols in water by a polyaniline-coated $\mathrm{Pt}$-fiber using experimental design. Analytica Chimica Acta, 581(1): 71-77.

Nell, M., Votsch, M., Vierheilig, H., Steinkellner, S., Zitterl-Eglseer, K., Franz, C., Novak, J., 2009. Effect of phosphorus uptake on growth and secondary metabolites of garden sage (Salvia officinalis L.). Journal of the Science of Food and Agriculture, 89(6): 1090-1096.

Nieto, G., 2017. Biological activities of three essential oils of the lamiaceae family. Medicines, 4: 63 .

Nostro, A., Papalia, T., 2012. Antimicrobial activity of carvacrol: Current progress and future prospectives. Recent Patents on Anti-Infective Drug Discovery, 7(1): 28-35.

Novy, P., Davidova, H., Serrano Rojero, C.S., Rondevaldova, J., Pulkrabek, J., Kokoska, L., 2015. Composition and antimicrobial activity of euphrasia rostkoviana hayne essential oil. Evidence-Based Complementary and Alternative Medicine, $1-5$.
Pereira, T.S., de Sant'Anna, J.R., Silva, E.L., Pinheiro, A.L., de Castro-Prado, M.A.A., 2014. In vitro genotoxicityof Melaleuca alternifolia essential oil in humanlymphocytes. Journal of Ethnopharmacology, 151: 852-857.

Perry, N.B., Anderson, R.E., Brennan, N.J., Douglas, M.H., Heaney, A.J., McGimpsey, J.A., Smallfield, B.M., 1999. Essential oils from Dalmatian sage (Salvia officinalis L.): variations among individuals, plant parts, seasons, and sites. Journal of Agricultural and Food Chemistry, 47(5): 2048-2054.

Philis, J.G., 2005. The S1 $\leftarrow$ S0 spectrum of jet-cooled p-cymene. Spectrochimica Acta Part A: Molecular and Biomolecular Spectroscopy, 61(6): 1239-1241.

Ramezani, S., Rezaei, M.R., Sotoudehnia, P., 2009. Improved growth, yield and essential oil content of basil grown under different levels of phosphorus sprays in the field. Journal of Applied Biological Sciences, 3(2): 105-110.

Sökmen, A., Sökmen, M., Daferera, D., Polissiou, M., Candan, F., Ünlü, M., Akpulat, H.A., 2004. The in vitro antioxidant and antimicrobial activities of the essential oil and methanol extracts of Achillea biebersteini Afan. (Asteraceae). Phytotherapy Research: An International Journal Devoted to Pharmacological and Toxicological Evaluation of Natural Product Derivatives, 18(6): 451-456

Tang, X., Chen, S., Wang, L., 2011. Purification and identification of carvacrol from the root of Stellera chamaejasme and research on its insecticidal activity. Natural Product Research, 25(3): 320-325.

Timbermont, L., Lanckriet, A., Dewulf, J., Nollet, N., Schwarzer, K., Haesebrouck, F., Ducatelle, R., Van Immerseel, F., 2010. Control of Clostridium perfringens-induced necrotic enteritis in broilers by target-released butyric acid, fatty acids and essential oils. Avian Pathology, 39: 117-121.

Tuncturk, R., Tuncturk, M., 2006. Effects of different phosphorus levels on the yield and quality components of cumin (Cuminum cyminum L.). Research Journal of Agriculture and Biological Sciences, 2(6): 336-340.

Tübives, 2021. Türkiye Bitkileri Veri Servisi. http://www.tubives.com, Erișim: 04.03.2021

Vas, G., Vekey, K., 2004. Solid-phase microextraction: A powerful sample preparation tool prior to mass spectrometric analysis. Journal of Mass Spectrometry, 39(3): 233-254.

Yaşar, S., Dişli, M., Sonkaya, Y., 2016. Comparison of volatile components of Thymus zygioides Griseb. var. lycaonicus (Celak.) Ronniger due to reaping time. Turkish Journal of Forestry, 17(2): 94-98. 